Energy and Sustainability VIII 63

\title{
ENERGY-RELATED HOUSING RENOVATIONS FROM AN EVERYDAY LIFE PERSPECTIVE: LEARNING FROM PORTUGUESE HOMEOWNERS
}

\author{
MARIA ISABEL ABREU, RUI A. F. DE OLIVEIRA \& JORGE LOPES \\ School of Technology and Management, Polytechnic Institute of Bragança, Portugal
}

\begin{abstract}
Changing the attitudes of existing building users towards sustainability is a paramount strategy towards a low-carbon society. One of the challenges lies in encouraging owners to renovate their houses. Recent studies have pointed out the relevance of the homeowner's social context which, more often than not, outstrips public awareness campaigns and even techno-economic advice. The decision to renovate seems to emerge from deep social issues rather than exclusively from the simple analysis of investment return or environmental awareness. The present study aims to bring discussion to these social subjects for single-family buildings in Portugal and identify key factors which may influence decision making. Firstly, a set of in-depth interviews were conducted with a group of experts. Subsequently, and based on the interviews, a group of Portuguese single-family homeowners, who undertook at least one energyrelated piece of work, were surveyed. Together with the survey a structured observation method was put into practice. The results revealed that homeowner's stage of life, personal/family events, everyday practices, lifestyles and social network framework have a major influence on their prime intention to renovate their homes. The desire to maintain or change the routines and the way family uses the indoor spaces are common drivers, however, motivations linked to aesthetics, trends and social status were revealed to be extremely influencing. The decision process is negotiated inside the family involving not only desired domestic life conditions but also skills, understandings and social values shared by the dwellers. The energy-related renovations take place, in many cases, as a consequence of a previous decision to renovate, taken due to other reasons. It does not consist of one single event but is rather part of a practice of a "little-by-little renovation". Motivational policies should be drawn considering the energy-related renovations as any other type of renovation and not separately from the others.
\end{abstract}

Keywords: energy-related renovation, energy policy, houseowners, energy efficiency, decisionmaking, everyday life, social practice, drivers, residential building stock, Portugal.

\section{INTRODUCTION}

The housing stock represents $74 \%$ of the European building stock and is mostly inhabited by the owners: $70 \%$ in the European Union; $67 \%$ in the United Kingdom; $89 \%$ in Denmark and $74.7 \%$ in Portugal [1]. There is no doubt that reduction of $\mathrm{CO}_{2}$ emissions from owneroccupied buildings is of major importance. In Portugal, the greatest potential for savings is in residential and services. This sector alone represented $42 \%$ of the contribution to primary energy saving goals of the total predicted for 2016 [2]. The implemented policies have failed to result in an execution rate of improvement procedures in the existing residential buildings that enables meeting the required targets [3], [4]. First of all, we must highlight that the common premise commonly used to support the arguments motivating homeowners has been that they wish to renovate in order to save energy and money, but are prevented from doing so mostly by financial constraints and by doubts regarding energy saving, financial return and the reliability of the professionals who will execute the works. These bases have been the support to behavioural sciences (and consequently to national policies) used to explain human behaviour regarding buildings energy efficiency. They have been mostly anchored in microeconomic issues, in the dynamics of owners' uptake of technology [5], on consumer behaviour and marketing [6]. Behavioural science has treated homeowners as individuals 
who make rational choices in order to obtain certain results which are dissociated from home life [7]. This representation of homeowners' decisions to achieve goals and isolated from other family decisions is part of a speech centred on individual choice [8]. Therefore, recent approaches to the problem call for social science in order to conceptualise the study of decision-making regarding the renovation of the building stock as a process emerging from home life circumstances and subjected to several levels of influence [9]-[12]. This study aims to get an in-depth knowledge about energy-related renovation of single-family owneroccupied houses as part of the daily and the social sharing practices which constitute Portuguese family life.

\section{CONTEXTUAL BACKGROUND ABOUT BEHAVIOURAL SCIENCE}

Behavioural science has been based on the assumption that it is necessary to identify barriers and motivations and that these will account for homeowners' decision to renovate housing buildings with energy efficiency. The formal models used to understand this process have most often emphasised the advantages of energy efficiency and the financial issue. Personal and contextual influences have been used to explain the reasons behind homeowners' low uptake. This analysis targets decision-makers and not differentiated dwellers, energy efficiency and not indoor spaces improvements, the extraordinary and not everyday activity involving shared objects, skills and understandings, one-time renovation and not the "littleby-little renovation" and buildings and not homes with meaningful spaces [7]. Behavioural sciences are limited to the decisions rather than the process preceding them or the domestic context from which they emerge [7]. Nair et al. [13] suggested that there could be other factors that influence energy efficiency investment decisions such as lifestyles. Judson and Maller [10] also claim that policies only focusing on technical intervention issues have a limited scope. This kind of renovation cannot continue to be seen as a mere exercise of integrating technology into buildings. Stern [14] had previously identified the lack of interdisciplinarity in the studies about this subject and Lutzenhiser [11] criticises the restrictive model which has been used in policy-making regarding buildings' energy saving as it leaves out contributions from social science. Recently, Tjørring and Gausset [15] gave a reinforcement on this issue suggesting that social aspects often weighted more than economic aspects.

\section{SOCIAL SCIENCE IN ENERGY RESEARCH: RECENT EVIDENCE}

Energy use has a social nature [6]. Energy provides useful services allowing the functioning of normal social activities which are part of individuals' home life [16] and such practices are reproduced throughout time and space [17]. Comfort and convenience have become, according to current patterns, ordinary demands which impact on energy use [18].

The roles of social science in interdisciplinary energy research consists not only in dealing with social complexities encountered in pursuing aims driven mostly by engineering but also assisting in framing priorities, questions and options [19]. There are a representative number of studies that introduced social science to the investigation on housing renovation to reduce energy consumption considering homeowners' daily life [20]-[27]. The studies suggest that such practices surpass environmental concerns and the reduction of energy consumption. Renovating a building is an action which is negotiated within the family in response to the performance of family practices [10] where households' skills and home meanings have a specific role [17], [25]. Palm et al. [28] advise that energy consumption in households with more than one member is a collective rather than individualized process and call for in-depth analysis of household couplings. Wilson et al. [7] go further and claim that encompassing the decision-making process within home life conditions brings those deepest influences which 
are at the core of decision-making processes. They argue that renovating is oftentimes a way for dwellers to solve conflicts and tensions, achieve goals, take up opportunities and give wings to personal and family aspirations. The decisions to renovate are processes and such processes emerge from and take place within the daily home life circumstances (sometimes also triggered by extraordinary events). In many cases, the decision to adopt energy efficiency measures emerges later in the process to renovate others parts [29].

Homeowners' level of involvement in the renovation process (oftentimes doing some of the tasks themselves) also constitutes one of the reasons pointed out for starting the process. The renovation becomes part of their daily life, making them feel emotionally more attached to the house and often leading to touches of innovation [30].

In 2014, Gram-Hanssen [24] exposed other very important issue. Aesthetical and functional issues come first in the list of Danish homeowners. An example of this is the remodelling of kitchens and bathrooms, which continue to be the top preferences, while not leading to any investment return. These renovations are part of social norms regarding an image of prestige. Visible renovations are prioritized and frequently made before other nonvisible measures although they know they are not economically reasonable [15]. Trends, status and lifestyles are factors this author also refers as boosters to renovation. Bravo et al. [31] demonstrated that renovation works are normally linked to aesthetic aspects of the house.

Wilson et al. [7] went further and identified levels of influence in the decision-making. The ultimate influences are at the core of the initial intention (e.g. why renovate?) and behavioural science is failing to work with them. Gram-Hanssen [24] mentioned the following example: if the family decide to change the windows or the roof, calculations on the energy saved as well as on the investment return may be decisive to choose the thickness of thermal insulation or the technical framing and glass solution. However, as far as the decision to renovate is concerned, investment return is rarely an influence.

Finally, Wilson et al. [7] consider that policy-makers should acknowledge that renovations in housing buildings are predominantly an improvement and adaptation of homes indoor spaces so as to better execute home life tasks and practices. They should incentivize and support the energy efficiency measures included in such renovations. The authors also recommend that researchers identify specific conditions of home life which are related to renovation activities. The homeowners may be encouraged to adopt energy efficiency measures in connection with these renovations even because the adoption of energy efficiency measures is often cost-effective during a general renovation [32].

\section{MATERIALS AND METHODS}

The analysis reported in this paper is based on a preliminary stage of a larger scale research project about the home-related practices and social perspective of energy-related renovation of private homes. On a preliminary phase and to cope with the aims of this study, a qualitative method was considered fundamental to in-depth knowledge, identifying social conditions and motivations and explaining them in more detail. A minor quantitative analysis complements the qualitative research results. A presential survey was made in 2016-2017 to a group of 57 Portuguese homeowners of single-family houses (included the homeowners' partners that were at home when the survey was made). Given the number of respondents, the results could be, eventually, not demonstrative of all cases and are limited to the universe of the circumstances found in the survey. Previously, three in-depth interviews to experts (informants) were also made to help to prepare the survey structure (the long-time experience was the main criteria). The survey was also tested in three homeowners to guarantee if all the important aspects were covered in order to answer the investigation questions and to see if the questions were clear. They were invited to put some comments about confusions, 
problems or recommendations. Based on this feedback, the final version of the survey was put into action at the home of the respondents to get a personal contact with them and their family. This option allowed face-to-face interaction, capture of both affective and cognitive aspects and gave the researcher the opportunity to clarify or explain the question for better responses. Therefore, it was implemented a qualitative research method involving structured behavioural observation - observational survey. The questions were both open-ended and closed-ended. The number and type of energy-related renovations made and the motivation factors where the central topics explored. The interviewer took notes about homeowners and their partners reactions to the questions using observation guides (parameters to be observed were clearly pre-defined) in order to gather data on individual behaviour or interactions between participants (facial expressions, oral comments and positive and negative stimuli).

The sample were selected, initially, consulting the municipality services to identify districts with single-family building typologies constructed between 1970 and 2000 (buildings more than 15 years old). Three urban municipalities in the North of Portugal (severe Winter Climatic Zone) were considered for a preliminary approach. The homeowners were first contacted personally at their home and then was scheduled a meeting. Knowing if they had already performed at least one type of energy-related work was the question made to the homeowners in the initial contact. Only the ones in this condition made part of the sample to understand more accurately the motivations of building renovating profile homeowners. The homeowners' ages were between 29 and 75 years old $(12.1 \%$ have less than $40 ; 69.5 \%$ were between $40-65$ and $18.4 \%$ more than 65$)$ and $58.1 \%$ were males and $41.9 \%$ females. As regarding the households' size, they had from 1-6 members, with $75.5 \%$ of them having children living at home. There were homeowners from all educational levels in the sample (60.5\% with a secondary or high school level) and $78.1 \%$ were employees. The average household income was medium to high level. The houses were, in general, with a regular/good maintenance appearance and have the characteristics of middle-class houses. In addition, $79 \%$ of the houses were built or bought and $21 \%$ inherited.

\section{RESULTS AND DISCUSSION}

\subsection{An overview about energy-related renovations}

Energy-related renovations were considered all the physical changes to the building that involve improvements in the thermal insulation of buildings envelope and in the air and water heating systems. All the other types of renovations were considered the ones that change building aesthetic and functionality that may induce or include energy related improvements. The principal renovation works, frequency and order of priorities adopted by the respondents are in Fig. 1. The aesthetical and indoor renovations are the priority followed by the envelope and outdoors. As far as renewable energies are concerned, the thermal solar collector and the heat recovery systems that close the fireplace are the preferred.

\subsection{Social and daily home life practices influencing energy-related renovations}

Situations concerning the maintenance, malfunction and failure of buildings components were mentioned in $70.5 \%$ of the cases as the trigger to renovation works. Proceeding with an energy renovation normally stems from a renovation conducted out of necessity. One of the examples given by the respondents was the initial need to replace the roof tiles which resulted in the adoption of thermal insulation. Some of the respondents reported a need to solve problems related to condensation in window frames as triggering their replacement. Also, the 


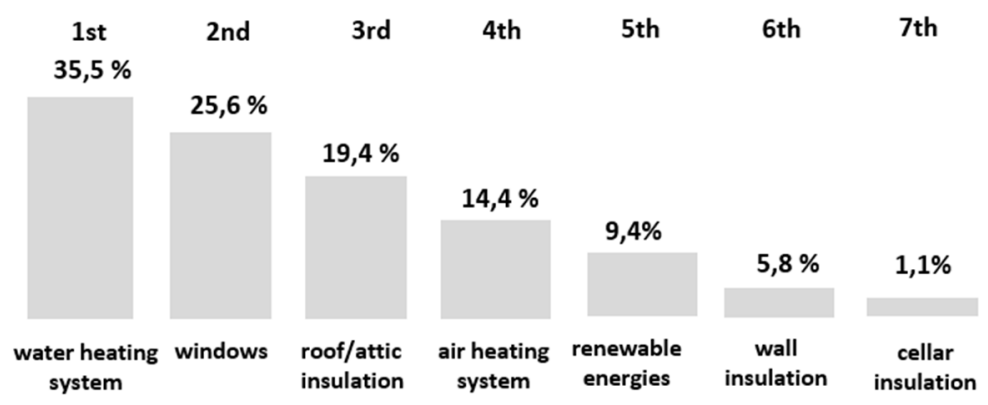

Figure 1: Frequency and preference of energy-related renovations works.

need to replace the air heating system due to failure or in order to achieve higher efficiency made homeowners aware that the next step would be to act on the building envelope thermal insulation in order to reduce heat loss and monetize the new system efficiency.

The analysis conducted showed that Portuguese homeowners start by doing small, sometimes low-cost, renovations out of necessity (not necessarily energetic-related) and gradually continue with other renovations throughout the time (79.3\% of the respondents). Some actions encourage and trigger others, depending on the time and money available at that stage, on certain given circumstances of domestic life and on the personal ambition to do certain renovations. In general, it is not only possible to talk about one single event but about some "little-by-little renovation" dynamics, according to the family needs and daily home life actions. From the analysis made to the sequence of measures taken by the respondents throughout the years, small cost-efficient energy efficient measures (even nonphysical measures) induced more extensive measures.

Nevertheless, there are some key moments in Portuguese respondents' stage of life that can led to large energy-related renovations. The moment of buying a second-hand house, deciding to live in an inherited house, new relationship, new child, children moving out, the beginning of retirement, widowhood or the beginning/end of a life cycle (emotional stress, family conflicts or disturbance) were important moments detected. Note that $68 \%$ of the respondents, who acquired their second-hand home, did some improvement works when moving in, so as to ensure homeowners' comfort and aesthetics requirements. Personal events seem to generate the need to change something in the house. The respondents with prior experiences in some kind of renovation measures showed more determination and less fear to make more energy improvements in the house $(64 \%$ of them intend to continue renovating). The savings experienced from the adoption of some previous measures has made them more aware of what actions to take next. The lack of experience of some respondents made them acknowledge their reluctance, although they are sensitive to the issue. Most respondents under 50 years old have a shorter timespan for experiences, but as they are in the prime of life, they stated to have plans for the future and aspire to improve their dwelling. Youngers homeowners reveal more enthusiastic.

Another interesting aspect was the homeowners surveyed who stated that they like to plan the improvement of their dwellings, get personally involved in the choice of energy efficient solutions and in the execution of some tasks. They take pleasure from the process as much they do from the result. Pre-acquired knowledge has a paramount influence in these homeowners. They are better informed and are more likely to enjoy DIY tasks. This tendency was observed in a higher scale among the homeowners under 50 years old with a more educational level. They also stated that the construction professionals did not always provide 
them with the best advice or best solutions. The female respondents, especially those under 50 years old, referred that they like to get involved in the process, but mostly regarding aesthetic issues only.

The homeowners' life stage also seems to be significantly relevant to their attitude. The younger generation of respondents (considered under 50 years old) have grown with a different sensibility and therefore, show higher environmental awareness, more knowledge of energy efficiency and innovative systems and technologies. They have more daily habits connected to this issue and wish to have an environmentally friendly home. On the other hand, the respondents over 50 years old generally stated that what motivates them the most towards renovating is the comfort, safety, easy use (barrier-free) and aesthetics that the building resources provide to their daily life. The physical demands of home life tasks are paramount to the respondents over 65 years old. In this age range, people are more sensitive to temperature variations, they spend more time at home and have more physical limitations. As an example, a number of homeowners stated to have replaced their heating systems with central heating systems, which are more practical and user-friendly (with central controlling devices) and require less physical effort. The switch to more energy efficient equipment using renewable energies or electricity is also a measure frequently mentioned as it they consider less dangerous than gas and more user-friendly for daily use than biomass. The respondents who also gave importance to aesthetics, declare that they are in a position in life where they want to do what they like best and do not mind spending money on it.

Another relevant issue found is that in the renovation project of a residential building there is a family involved, with differentiated individuals and corresponding opinions. The discussion of opinions and the need to reach consensus is acknowledged by the homeowners. Female respondents have more aesthetic and architectural aspirations while male respondents are more concerned and willing to acquire renewable and energy saving technologies. Although the technical solutions do not per se persuade homeowners, the male respondents stated that they might be appealing enough to leverage the renovation process. Most female subjects do not like the untidiness and changes caused by a building renovation in the family daily life (therefore the "little-by-little renovation" appeal), but they are more demanding as far as indoor comfort temperatures are concerned. On the other hand, the male subjects seem more concerned with the investment financial risk.

The data also revealed that the interventions are also motivated by a desire/necessity to maintain or change family life ideals, domestic routines and the way homeowners live their home. Some subjects stated that they intend to improve family socialization practices by creating comfortable, relaxing and informal spaces where the family can gather. Others mentioned a will to host and entertain their families and friends. More natural light and space in the living areas, adopting open spaces like dining room/kitchen, and new rooms for guests, are examples of the home improvements mentioned. In some cases, it was the need to adapt the space to new working and studying practices that led to restructuring indoor spaces. Consequently, such new comfort demands led to pondering ways to improve energy efficiency (envelope thermal insulation and air heating system).

Foreseeing and anticipating changes in home life dynamics was also found to be a factor triggering the wish to renovate, with implications in the use of energy. The need to share spaces was also stated to create conflicts and tensions which can be solved through renovation. Some of the respondents mentioned higher comfort demands due to: household fluctuations (a new child or the return of grown-up children to the family home); school-age children at home or homeowners' retirement. The more time family members spend at home, the higher their energy use. Hence, children and elderly play an important role. A percentage of $72.2 \%$ of the respondents under 50 years old stated that increasing their children's level of 
comfort may be the triggering factor to proceed with home renovations. Nowadays, there are high requirements regarding the temperature of children's bedrooms and living rooms, which implies costs. The elderly, who spend more time at home, also require adequate and comfortable spaces. The respondents under 50 years old also showed concerns with comfortable additional spaces for schoolchildren to play and study. Some respondents (the generation with children up to 18 years old) stated that the current generation of children and teenagers makes an intensive use of their bedrooms, where they have a computer and sometimes even a television set. This means one more room which needs and consumes energy during the day, contrarily to what happened in the past, when most home life activities were held in the kitchen and living room. Generalised comfort in all the household spaces has become a requirement of modern times. This has led homeowners to ponder the adoption of energy efficient central heating systems with the use of cheaper energy or renewable ones.

As far as physical daily tasks are concerned, renovations might oftentimes be triggered by the homeowners' wish for higher comfort in the performance of these tasks. For example, the female respondents claimed for more user-friendly equipment that they need to operate daily. This is the reason given for replacing some appliances with more energy efficient ones (air heating systems, for example) fitted with automatic air temperature control systems. One frequent remodelling action typically conducted in living rooms is to close open fireplaces and install a biomass heat recovery system (e.g. pellets), which is cleaner and more userfriendly. This solution was also considered to be a security measure by the respondents over 50 years old.

One of the most relevant motivations mentioned by the Portuguese respondents concern their ambitions related to the building aesthetics, lifestyle, social status and prestige. The energy-related renovations that brings a better appearance to the house, outdoor and indoor, are very attractive to the homeowners in general (replacement of windows, for example). Undoubtedly, residential buildings are also the expression of the family's identity and oftentimes, dwellers no longer identify with the image that the building transmits. This was another solid reason given by Portuguese respondents for the implementation of physical changes in the buildings, which bring about energy improvements as an additional benefit. Several of the respondents were concerned about the way the home was perceived by neighbourhood. There is a visible trend for the measures connected to energy efficiency to be noticeable to the community which are, frequently, the first ones to be implemented. The adoption of new technologies and renewable energies has been acknowledged as one of most important sign and expression of modernity and environmental awareness (and they are visible). Fashion and trends created by industry (advertising and catalogues) was recognized also as a driver by a great percentage of homeowners. It seems from the analysis of the data that energy efficiency starting to be seen as a trend by the Portuguese respondents and to be considered by homeowner as an instrument to make comparisons with what society defines as an ideal home. One of the favourite renovation actions is the remodelling of kitchens, which are spaces of intense use and also social prestige. Never pay back but provide useful services, convenience and a personal fulfilment. Such renovation sometimes triggers the replacement of household appliances with lower energy consumption devices (for example, the need to the relocate the water heating system may end up leading to its full replacement). The same happens with the renovation of façades (walls and principally windows) and surrounding outer spaces, seen as transmitting something about the building dwellers. Similarly, the renovation of façades led to the application of thermal insulation.

With regard to community life, some respondents admitted that seeing energy efficiency measures being adopted by their relatives, friends and neighbours encouraged them to do the 
same. The communication within the community network that Portuguese homeowners ends up playing a crucial role in the motivation they have to renovate.

Also noteworthy in the results of this study was the observed will to adopt renovation measures in buildings with higher sentimental value (e.g. inherited buildings). The inherited houses revealed a higher number of non-monetary (without financial return) and aesthetical improvements compared with others cases. As these properties are affectively meaningful to their owners, the set of renovation measures adopted might not even imply any financial return, fact that is irrelevant to the respondents. The choice seems to be emotionally oriented, in this particular case, but these kind of influence were also detected, more or less, in the decisions for all the other types of homes.

Table 1 summarises the influences, together with their relevance, related with homeowner's daily life at home and social practices and norms identified in this preliminary study which reveal to be at the core of decision-making processes regarding the renovation of Portuguese single-family buildings and which had subsequent implications for the adoption of energy-related measures. Some influences stand out: the stage of life and beginning/end of life cycles; family comfort concerns; lifestyles; trends and social standards.

\subsection{Practical implications for energy policies}

Social sciences have a significant role for informing new policy approaches [12], nevertheless, social analysis is not underlined in the Portuguese public policies about energy

Table 1: Influences, and their importance to the respondents, to renovate single-family buildings with implications in the adoption of energy efficient measures.

\begin{tabular}{|c|c|c|}
\hline & $\begin{array}{l}\text { Influencing factors for home renovations with } \\
\text { consequences in energy efficient improvements }\end{array}$ & $\begin{array}{c}\% \\
\text { respondents }\end{array}$ \\
\hline \multirow{3}{*}{ 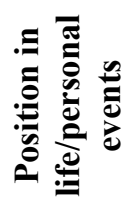 } & Stage of life and the beginning/end of a life cycle & $67.4 \%$ \\
\hline & After a personal/family event & $42.2 \%$ \\
\hline & Experience in the adoption of previous measures & $50.5 \%$ \\
\hline \multirow{9}{*}{ 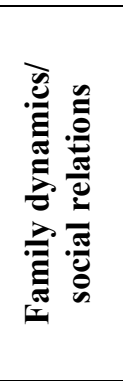 } & An active participation in the renovation (homeowner's skills) & $30.2 \%$ \\
\hline & Roles, relationships and opinions/conflicts within the family & $55.5 \%$ \\
\hline & Change/maintain the daily practices and the family life ideals & $40.5 \%$ \\
\hline & Concern with the family comfort conditions & $82.3 \%$ \\
\hline & Fluctuations in the household composition & $55.4 \%$ \\
\hline & Indoor conditions for the family and friends to socialize & $30.2 \%$ \\
\hline & Safety and easy-use to manage the home facilities & $38.2 \%$ \\
\hline & Building not adapted to dwellers' physical abilities & $10.3 \%$ \\
\hline & Higher comfort when performing domestic tasks & $40.0 \%$ \\
\hline \multirow{7}{*}{ 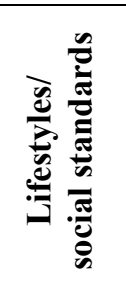 } & Improvement of building aesthetics /personal tastes & $70.5 \%$ \\
\hline & Achieve social status and new lifestyle & $68.3 \%$ \\
\hline & Fashion and trends created by products industry (catalogues) & $66.4 \%$ \\
\hline & Building identity not compatible with homeowners' identity & $58.3 \%$ \\
\hline & Measures implemented in friends and neighbors' homes & $55.2 \%$ \\
\hline & Sentimental meaning and value of the building & $52.4 \%$ \\
\hline & Interest of their children to live in their home in the future & $28.4 \%$ \\
\hline
\end{tabular}


efficiency for existent buildings. The most recent National Plan for Energy Efficiency [33] reinforces the strategy of mobilize investments to the renovation of the national buildings stock, nonetheless, it keeps on relying on: the usual "save energy" argument used both in the Energy Performance Certificate System (EPCS) and in the informational and awareness campaigns and on financial programmes. All of these tools conceptualized as distinctive and partitioned from other home improvements with which homeowners are engaged throughout the years. If the everyday life at home aspects are involved in dynamic of home improvement, energy-related renovations must be considered in the same way.

The EPC requires that major building renovations be a minimum on efficient classes. The problem is that Portuguese homeowners make primely step by step home improvements, not necessarily in one single action, and where energy efficiency can be included or not. Until now, the contribution for the national energy goals is limited to the implementation of the improvement measures identified on energy certified homes [2]. Nevertheless, Portuguese homeowners still see the EPC as a bureaucratic and complex document, useful (in theory) but in practice with some drawbacks [22], [34]. The EPCs, as all other government informational policy tools (campaigns and informational platforms), lays on the energy saving and profitability arguments to convince the homeowners nonetheless these latter tend to pay more attention to total upfront costs [35] and are sceptical about the costs presented in the EPC [34]. Few Portuguese homeowners require the EPC voluntarily and the majority of the ones that required did not implement the improvement measures recommended [34].

The latest National Building Renovation Plan [2] relies on four specific measures: solar thermal for domestic hot water (DHW); green heat (biomass use in fireplace heat recovery systems); efficient window and thermal insulation. Situating this challenge in a broader understanding, a new conceptualization of these measures can be made. In this study, the Portuguese respondents were willing to perform visible and aesthetical renovations that invoke an image of social status and prestige. The solar thermal for $\mathrm{DWH}$, and other renewable energy systems, in general, and the efficient windows are visible measures, therefore, promoting them in connection with the homeowner's daily life influences linked with lifestyles and social standards could be more accurate strategy. Product industries could be an important partner to awaken the will of the homeowners to the energy renovations creating, as they do for other products, new trends, using appealing images in catalogues with new home solutions, for example. The green heat could be promoted in association with aspects like safety, high comfort when performing domestic tasks and easy-use to manage the home facilities. The roof/attic insulation is not as much as problematic as the wall insulation but both are less visible measures and then it seems not so prioritized by homeowners. These improvements could be incentivized in homeowners that: had implemented previous and related measures (for example, efficient air heating system); have an intense household dynamic that originate high comfort demands and energy consumption (children and older householders) and have family socializing ideals. Finally, but no less important, two imperative issues are: to encourage the start of the step by step renovation process (including energy-related measures or not), even if using an initial small measure, and make all these energy efficiency measures as fashionable as many other areas in homeowners' lives. There are key opportunities for the energy advisor to work with Portuguese homeowners. They could be trained to target homeowners on these specific aspects of their lives because that how it is more likely that energy renovations happen. A special energy advice (door-to-door or available at the municipality) need to reach the homeowners' problems and concerns in order to address the most important aspects for them. Consequently, this calls for more tailored and creative strategies to be developed. 
In almost all the European countries, motivational policies are also more focus on technoeconomical aspects using the EPCS than in the social and everyday practice context of energy-related renovations [22]. However, there are some countries that are making small steps and leading by the example. Working with the social framework calls for more proximity to the homeowners and better interpersonal communication [13]. Proximity polices and local level actions, with local bodies involved, can play an important role [3]. Local governance strategies taken by some front-runner municipalities try to engage the homeowners with energy efficiency. Personalized information and consultation, group tours, public-private partnerships with local companies; local campaigns and energy advisors prepared with social and communication skills to reach homeowners' needs are examples [3], [13], [22], [24], [30]. Local offices for free energy advice and consultancy and local workshops/exhibitions with the participation of opinion leaders is a work in progress in Sweden [13]. In Denmark, where EPCs have the longest implementation, promote energyrelated renovations by offering free energy advice at home is a strategy already in the field, studied and monitored on a social and everyday life perspective [15].

\section{CONCLUSIONS}

As we saw previously, the energy-related renovation seems to be strongly related with everyday life of Portuguese homeowners. Houses are the reflect of homeowner's life stage, family dynamics, social relationships, lifestyles and social rules. This paper aimed to bring social science to the discussion in order to get an in-depth knowledge about how Portuguese homeowners' home life conditions and everyday social practices influence energy-related renovations in single-family buildings. This study contradicts the assumption of this is an investment that is guided fundamentally by financial restrictions. The homeowners regard several daily life and non-profitable factors when they decide to renovate which can increase the motivation to implement energy efficient measures. Renovations for reducing Portuguese residential buildings' energy consumption must be seen by policy-makers as part of a continuous process of gradual adaptation of the building to family life. The most important highlights can be recorded. Energy efficiency renovation cannot be seen as one single isolated event, but as a "little-by-little" practice conducted jointly with or induced by other remodelling approaches involving multiple aspects of the homeowner's daily life negotiated within the family. Encourage the start of this continuous and gradual process of renovation is highly important. One initial measure, even simple, can activate many others in the future. The results also demonstrate that is great the influence that aesthetic, trends and social standards have in homeowners' decision. Make energy efficiency a fashionable issue could be an interesting challenge for Portuguese policy-makers, without forgetting to work with the industries that have huge influence and know how to shape people tastes and tendencies. Something saw in a magazine or catalogue can be a powerful tool. Information and communication policies must be structured and adapted to the different social context of the homeowners and is expectable that local bodies can have an important role on that.

\section{REFERENCES}

[1] Eurostat, Distribution of population by tenure status, type of household and income group: EU-SILC survey. http://appsso.eurostat.ec.europa.eu/nui/show.do?dataset $=$ ilc_lvho02\&lang=en. Accessed on: 2 Nov. 2018.

[2] Direção Geral de Energia e Geologia, Estratégia Nacional para a Renovação de Edifícios, Direção Geral de Energia e Geologia: Lisboa, 2014. 
[3] Stieß, I. \& Dunkelberg, E., Objectives, barriers and occasions for energy efficient refurbishment by private homeowners. Journal of Cleaner Production, 48, pp. 250259, 2013. DOI: 10.1016/j.jclepro.2012.09.041.

[4] Gillingham, K. \& Palmer K., Bridging the energy efficiency gap: policy insights from economic theory and empirical evidence. Review of Environmental Economics and Policy, 8(1), pp. 18-38, 2014. DOI: 10.1093/reep/ret021.

[5] Whitmarsh, L. et al., Public Attitudes, Understanding, and Engagement in Relation to Low-Carbon Energy: A Selective Review of Academic and Non-Academic Literatures. Research Councils UK (RCUK): London, 2011.

[6] Moezzi, M. \& Janda, K.J., From "if only" to "social potential" in schemes to reduce building energy use. Energy Research and Social Science, 1, pp. 30-40, 2014. DOI: $10.1016 /$ j.erss.2014.03.014.

[7] Wilson, C., Crane, L. \& Chryssochoidis G., Why do homeowners renovate energy efficiently? Contrasting perspectives and implications for policy. Energy Research and Social Science, 7, pp. 12-22, 2015. DOI: 10.1016/j.erss.2015.03.002.

[8] Maller, C.J. \& Horne, R.E., Living lightly: How does climate change feature in residential home improvements and what are the implications for policy? Energy Research and Social Science, 1, pp. 41-48, 2014.

DOI: $10.1080 / 08111146.2011 .539514$.

[9] Gram-Hanssen, K., Retrofitting owner-occupied housing: remember the people. Building Research and Information, 42, pp. 393-397, 2014.

DOI: 10.1080/09613218.2014.911572.

[10] Judson, E.P. \& Maller, C., Housing renovations and energy efficiency: Insights from homeowners' practices. Building Research and Information, 42(4), pp. 501-511, 2014. DOI: $10.1080 / 09613218.2014 .894808$.

[11] Lutzenhiser, L., Through the energy efficiency looking glass. Energy Research and Social Science, 1, pp. 141-151, 2014. DOI: 10.1016/j.erss.2014.03.011.

[12] Gram-Hanssen, K. \& Georg, S., Energy performance gaps: promises, people, practices. Building Research and Information, 46(1), pp. 1-9, 2018. DOI: 10.1080/09613218.2017.1356127.

[13] Nair, G., Gustavsson, L. \& Mahapatra, K., Factors influencing energy efficiency investments in existing Swedish residential buildings. Energy Policy, 38(6), pp. 29562963, 2010. DOI: 10.1016/j.enpol.2010.01.033.

[14] Stern, P.C., Individual and household interactions with energy systems: toward integrated understanding. Energy Research and Social Science, 1, pp. 41-48, 2014. DOI: $10.1016 /$ j.erss.2014.03.003.

[15] Tjørring, L. \& Gausset, Q., Drivers for retrofit: a sociocultural approach to houses and inhabitants. Building Research and Information, 47(4), pp. 394-403, 2018.

DOI: $10.1080 / 09613218.2018 .142372 .2$

[16] Walker, G., The dynamics of energy demand: change, rhythm and synchronicity. Energy Research and Social Science, 1, pp. 49-55, 2014.

DOI: $10.1016 /$ j.erss.2014.03.012.

[17] Gram-Hanssen, K., Understanding change and continuity in residential energy consumption. Journal of Consumer Culture, 11(1), pp. 61-78, 2011. DOI: $10.1177 / 1469540510391725$.

[18] Shove, E., Comfort, Cleanliness, and Convenience: The Social Organisation of Normality, Berg: Oxford, 2003.

[19] Stirling, A., Transforming power: Social science and the politics of energy choices. Energy Research and Social Science, 1, pp. 83-95, 2014. 
DOI: $10.1016 /$ j.erss.2014.02.001.

[20] Guy, S. \& Shove, E., The Sociology of Energy, Buildings and the Environment: Constructing Knowledge, Designing Practice, Routledge: London, 2000.

[21] Karvonen, A., Towards systemic domestic retrofit: a social practice approach. Building Research and Information, 41(5), pp. 563-574, 2013.

DOI: $10.1080 / 09613218.2013 .805298$

[22] Bartiaux, F., Gram-Hanssen, K., Fonseca, P., Ozolina, L. \& Christensen, T.H., A practice-theory approach homeowners' energy retrofits in four European areas. Building Research and Information, 42(4), pp. 525-538, 2014.

DOI: 10.1080/09613218.2014.90025.

[23] Vlasova, L. \& Gram-Hanssen, K., Incorporating inhabitants' everyday practices into domestic retrofits. Building Research and Information, 42(4), pp. 512-524, 2014. DOI: $10.1080 / 09613218.2014 .907682$.

[24] Gram-Hanssen, K., Existing buildings: Users, renovations and energy policy. Renewable Energy, 61, pp. 136-140, 2014. DOI: 10.1016/j.renene.2013.05.004.

[25] Shove, E. \& Pantzar, M., Consumers, producers and practices: Understanding the invention and reinvention of Nordic walking. Journal of Consumer Culture, 5(1), pp. 43-64, 2005. DOI: 10.1177/1469540505049846.

[26] Strengers, Y., Nicholls, L. \& Maller, C., Curious energy consumers: humans and nonhumans in assemblages of household practice. Journal of Consumer Culture, 16(3), pp. 761-780, 2016. DOI: 10.1177/1469540514536194.

[27] Maréchal, K. \& Holzemerb, L., Unravelling the 'ingredients' of energy consumption: Exploring home-related practices in Belgium. Energy Research and Social Science, 39, pp. 19-28, 2018. DOI: 10.1016/j.erss.2017.10.025.

[28] Palm, J., Ellegård, K. \& Hellgren, M., A cluster analysis of energy-consuming activities in everyday life. Building Research and Information, 46(1), pp. 99-113, 2018. DOI: 10.1080/09613218.2017.1302225.

[29] Wilson, C., Pettifor, H. \& Chryssochoidis, G., Quantitative modelling of why and how homeowners decide to renovate energy efficiently. Applied Energy, 212, pp. 13331344, 2018. DOI: 10.1016/j.apenergy.2017.11.099.

[30] Galvin, R. \& Sunikka-Blank, M., The UK homeowner-retrofitter as an innovator in a socio-technical system. Energy Policy, 74, pp. 655-662, 2014.

DOI: 10.1016/j.enpol.2014.08.013.

[31] Bravo, G., Pardalis, G., Mahapatra, K. \& Mainali, B., Physical vs. aesthetic renovations: Learning from Swedish house owners. Buildings 2019, 9(1), p. 12, 2018. DOI: $10.3390 /$ buildings9010012.

[32] Janson, U., Passive houses in Sweden: Experiences from design and construction phase. Report EBD-T--08/9, Lund University, 2008. https://docplayer.net/22330807Passive-houses-in-sweden.html. Accessed on: 23 Feb. 2019.

[33] Plano Nacional de Ação para a Eficiência Energética (PNAEE). https://ec.europa.eu/energy/sites/ener/files/documents/pt_neeap_2017_pt.pdf.

Accessed on: 6 Apr. 2019.

[34] ADENE, Estudo de Opinião no Âmbito de uma Campanha de Sensibilização e Promoção da Eficiência Energética na Habitação Particular, ADENE. www.adene.pt/edificios/. Accessed on: 22 Feb. 2019.

[35] Baginski, J.P. \& Christoph, W., A Consumer decision-making process? Unfolding energy efficiency decisions of German owner-occupiers. HEMF Working Paper, No 08/2017, 2017. DOI: 10.2139/ssrn.3023997. Accessed on: 15 Feb. 2019. 